\title{
THEORY OF KNOWLEDGE
}

The Analysis of Knowledge

By Prof. Ledger Wood. Pp. 264. (London : George Allen and Unwin, Ltd., 1940.) 12s. 6d. net.

$\mathrm{T}^{\mathrm{H}}$

HIS work on the theory of knowledge has distinct merits. It is well arranged, well written and discusses all the subjects that should be discussed. The author deals with sense experience and memory, perceptual knowledge of 'things', of our own selves and other persons, the generalized knowledge of science and the knowledge implied in judgments of value. However, the book as a whole is disappointing.

In treating of perception the author criticizes the 'sense-datum' school of writers on grounds that certainly do not apply to Broad or Price. His own theory seems to be just the sense-datum theory with a slight change in terminology. He takes no account of what Gestalt psychology has to say about the objects of experience, and does not mention the important discussion in Blanshard's "Nature of Thought". $\mathrm{He}$ emphasizes at the beginning that all thought is referential, pointing to something beyond itself. One would suppose that this implied that relations are as real as any of the terms they relate, yet in Chapter vii he maintains that universals, including of course relations, are concepts, in the sense of being mental entities having no reference to anything beyond themselves. Worse still, in the last chapter he states a correspondence theory of truth, which implies a realist view of universals, since, as he says, truth is a property of propositions and since every proposition contains at least one universal term.

The best and most original feature of the book is the chapter on valuational knowledge, though it is confined to ethical judgments. The author perhaps makes undue use of the ambiguity of the term 'ideal', but he deserves credit for realizing that, however naturalistic a theory of knowledge may be, it cannot exclude value judgments, and for an ingenious method of including them.

If Prof. Wood could be induced to accept a realist view of universals (under the guidance of Peirce, Russell or Whitehead) to clear up some minor inconsistencies and to consider what Köhler and Blanshard have to say about facts of experience (only authors resident in his own country have been named), there are here the elements of a valuable theory.

\section{AIR NAVIGATION}

The Observer's Book on Astro-Navigation

By Francis Chichester. Part 1. Pp. 103. Part 2. Pp 83. (Observers' Books, Nos. 3 and 4.) (London : George Allen and Unwin, Ltd., 1940.) 2s. 6d. net each.

$\mathrm{I}^{\mathrm{T}}$ is commonly thought that the determination I of the position of a moving aircraft by means of astronomical observations is a difficult and complicated business. Actually, the principles involved are of extreme simplicity, and the working out of the observations takes at the most a few minutes with the aid of the Air Almanac and suitable altitude-azimuth tables to provide the solutions of the spherical triangles.

The observation of the altitude of a celestial body places the observer on a small circle, the centre of which is at the point on the earth's surface that has the body in its zenith at the instant of observation, and the radius of which is the complement of the observed altitude. The portion of this circle in the vicinity of the observer's position can be regarded as a straight line, and is known as a position line. The intersection of two position lines, allowance being made for the motion of the observer between the two observa tions, fixes the observer's position.

To draw the position line, any convenient position for the aircraft, somewhere near its estimated position, may be assumed. The position line will be independent of the assumed position. The surface navigator has been tied for too long to his dead reckoning position, which has no special virtue. In air navigation, an assumed position is adopted such that the altitude-azimuth tables require no interpolation. With the aid of the Air Almanac and the Astro-Navigation Tables, both prepared by the Nautical Almanac Office for the Air Ministry, the reductions are reduced to their simplest possible forms.

In these two small volumes, by an experienced air navigator, the methods and principles involved are explained in clear and simple language. Specimen pages from the Air Almanac are repro. duced and their use is described. A number of hypothetical observations (for which the astronomical 